\title{
The syntheses and NMR studies of hexadeca- and octaneopentoxyphthalocyanines
}

\author{
Namrta Bhardwaj, John Andraos, and Clifford C. Leznoff
}

\begin{abstract}
The syntheses of 3,6-dineopentoxyphthalonitrile and 3,4,5,6-tetraneopentoxyphthalonitrile are described. Condensation of these phthalonitriles with nickel chloride in $N, N$-dimethylaminoethanol yielded $1,4,8,11,15,18,22,25$ octaneopentoxyphthalocyaninato nickel(II) (3) and 1,2,3,4.8.9,10,11,15,16,17,18,22,23,24,25-hexadecaneopentoxyphthalocyaninato nickel(II) (7). The 'H NMR spectra of these phthalocyanines and the related 2,3,9,10,16,17,23,24octaneopentoxyphthalocyaninato nickel(II) (8) at temperatures from 205 to $330 \mathrm{~K}$ in toluene- $d_{8}$ exhibited various degrees of restriction of rotation of the neopentoxy groups. Compound 7 exhibited a single atropisomer at $235 \mathrm{~K}$.
\end{abstract}

Key words: neopentoxy substituted phthalocyanines, variable temperature NMR, restricted rotation.

Résumé : On décrit les synthèses des 3,6-dinéopentoxy-et 3,4,5,6-tétranéopentoxyphtalonitriles. La condensation de ces phtalonitriles avec du chlorure de nickel dans du $N, N$-diméthylaminoéthanol conduit à la formation des $1,4,8,11,15,18,22,25$-octanéopentoxyphtalocyaninato nickel(II) (3) et $1,2,3,4,8,9,10,11,15,16,17,18,22,23,24,25$-hexadécanéopentoxyphtalocyaninato nickel(II) (7). Les spectres RMN du ${ }^{1} \mathrm{H}$ de ces phtalocyanines et du $2,3,9,10,16,17,23,24$-octanéopentoxyphtalocyaninato nickel(II) $(8)$, à des températures de 205 à $330 \mathrm{~K}$, dans le toluène$d_{8}$, mettent en évidence des degrés de restriction à la rotation divers pour les groupes néopentoxy. Le composé 7 se présente sous la forme d'un seul atropisomère, à $235 \mathrm{~K}$.

Mots clés : phtalocyanines substituées par des groupes néopentoxy, RMN à température variable, rotation restreinte.

\section{Introduction}

Phthalocyanines have attracted a great deal of interest due to their unique properties that include extremely high thermal stability and chemical resistivity $(1,2)$. Traditionally, phthalocyanines have been used as dyes $(1,2)$ but recently they have found wide applications (3) in fields including liquid crystals $(4,5)$, chemical sensors $(3,6,7)$, photodynamic therapy of cancer $(3,8)$, and nonlinear optics (9-11). Applications of peripherally unsubstituted phthalocyanines are limited due their insolubility in common organic solvents and water $(10,11)$. Phthalocyanines possess an extended $\pi$ conjugated electron system which permits $\pi$ stacking (aggregation) between planar macrocycles, provided the distance between the macrocycles is small (10). Adding substituents to the periphery of the macrocycles increases their solubility since these substituents increase the distance between the stacked phthalocyanines and enable their solvation $(10,12)$. For many years the neopentoxy group has been used as a bulky substituent to enhance solubility (13-15).

Both 3-neopentoxy- (16) and 4-neopentoxy phthalonitriles (13) were available, but these mononeopentoxy phthalonitriles gave phthalocyanines as mixtures of regioisomers

Received 5 June 2001. Published on the NRC Research Press Web site at http://canjchem.nrc.ca on 7 February 2002.

N. Bhardwaj, J. Andraos, and C.C. Leznoff." Department of Chemistry, York University, Toronto, ON M3J 1P3, Canada.

${ }^{1}$ Corresponding author (telephone: (416) 736-2100 ext. 33 838; fax: (416) 736-5936; e-mail: leznoff@yorku.ca).
$(13,16)$. Unfortunately, for many applications, it is preferable to have both soluble and symmetric phthalocyanines. With this idea in mind, we set out to synthesize symmetrical polyneopentoxyphthaloniriles, for condensation to very soluble symmetrical multineopentoxy-substituted phthalocyanines. In the course of this work we noticed considerable restricted rotations of the neopentoxy substitutuents on the phthalocyanines as shown by NMR spectroscopy in temperature coalescence experiments

\section{Results and discussions}

\section{Synthesis}

Treatment of 2,3-dicyano-1,4-hydroquinone (1) with sodium methoxide in methanol at room temperature provided the disodium salt of 1 . This salt reacted with neopentyl tosylate in hexamethylphosphoramide (HMPA) at $110^{\circ} \mathrm{C}$ for 4 days to give 3,6-dineopentoxyphthalonitrile (2) in $62 \%$ yield. Condensation (17) of 2 with $\mathrm{NiCl}_{2}$ in $2-$ $N, N$-dimethylaminoethanol (DMAE) at reflux $\left(134^{\circ} \mathrm{C}\right)$ gave the symmetrical $1,4,8,11,15,18,22,25$-octaneopentoxyphthalocyaninato nickel(II) (3) in $22 \%$ yield (Scheme 1 ).

Using a different strategy (11) for the preparation of substituted phthalonitriles, commercially available 3,4,5,6-tetrafluorophthalonitrile (4) reacted with excess neopentyl alcohol in $N, N$-dimethylformamide (DMF) at $100^{\circ} \mathrm{C}$ in the presence of potassium carbonate to give 3,4,5,6-tetraneopentoxyphthalonitrile (5) in $65 \%$ yield. We recently described the preparation of the only other symmetrical neopentoxy-substituted phthalonitrile, namely, 4,5-dineopentoxyphthalonitrile (6) (18). Condensation of 5 and 6 as 
Scheme 1.<smiles>N#Cc1c(O)ccc(O)c1C#N</smiles><smiles>CC(C)(C)COc1ccc(OC(C)(C)C)c(C#N)c1C#N</smiles>

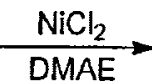

2

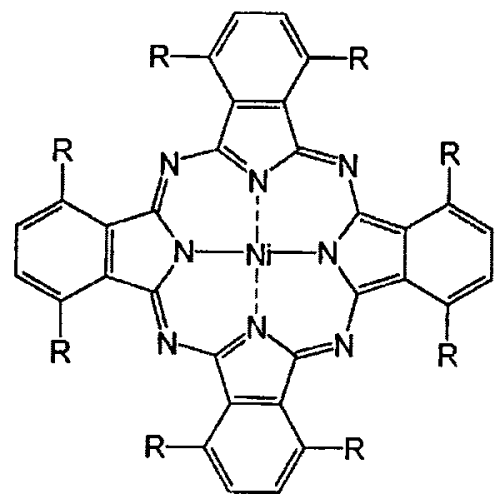

$3 \mathrm{R}=\mathrm{OCH}_{2} \mathrm{C}\left(\mathrm{CH}_{3}\right)_{3}$

above gave, respectively, the new $1,2,3,4,8,9,10,11,15,16$,$17,18,22,23,24,25$-hexadecaneopentoxyphthalocyaninato nickel(II) (7) in $15 \%$ yield and the previously reported (18) $2,3,9,10,16,17,23,24$-octaneopentoxyphthalocyaninato nickel(II) (8) (Scheme 2). Phthalocyanines 3, 7, and 8 were highly soluble in cyclohexane, benzene, toluene, tetrahydrofuran, and chloroform. The FAB and Maldi mass spectra of 3, 7, and 8 (18) all gave parent ion clusters. Comparison of the UV-vis spectra of 3,7 , and 8 (18) show the expected red-shifts in 3 and 7 due to the alkoxy substituents at the 1,4-positions. Thus, the $\lambda_{\max }$ of the $Q(0.0)$ band of 3 at $748 \mathrm{~nm}, 7$ at $758 \mathrm{~nm}$, and 8 at $672 \mathrm{~nm}$ is consistent with other studies, except that the $\lambda_{\max }$ of 7 at $758 \mathrm{~nm}$ is over $13 \mathrm{~nm}$ red-shifted compared to another less-hindered, branched hexadecahexyloxy- and hexadeca(2-ethyl)hexyloxy-substituted phthalocyaninato nickel (11). Highly hindered substituents at the 1,4 positions of 3 and even more so of 7 obviously enhances the red-shift of the $\mathrm{Q}$ band with the phthalocyanine $(\mathrm{Pc})$ nickel 7 representing one of the most red-shifted alkoxy-substituted Pc nickel known. Although
Scheme 2.

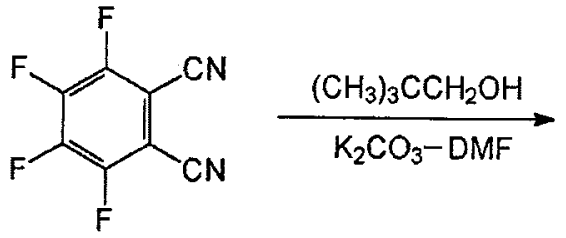

4<smiles>[R]c1c([R])c([N+]([O-])([O-])[O-])c([R])c(C#N)c1C#N</smiles>

$5 \mathrm{R}=\mathrm{R}^{\prime}=\mathrm{OCH}_{2} \mathrm{C}\left(\mathrm{CH}_{3}\right)_{3}$

$6 \mathrm{R}=\mathrm{H}, \mathrm{R}^{\prime}=\mathrm{OCH}_{2} \mathrm{C}\left(\mathrm{CH}_{3}\right)_{3}$

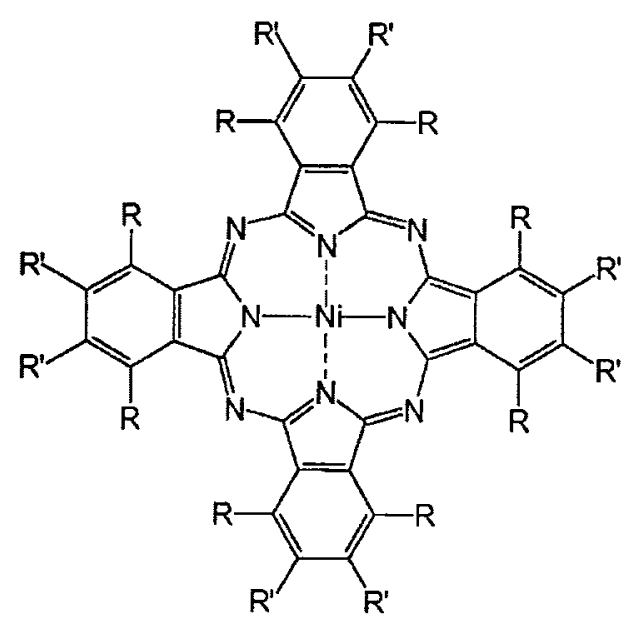

$7 \mathrm{R}=\mathrm{R}^{\prime}=\mathrm{OCH}_{2} \mathrm{C}\left(\mathrm{CH}_{3}\right)_{3}$

$8 \mathrm{R}=\mathrm{H}, \mathrm{R}^{\prime}=\mathrm{OCH}_{2} \mathrm{C}\left(\mathrm{CH}_{3}\right)_{3}$

metal-free 8 had been made (18), some attempts to make metal-free 3 and 7 were unsuccessful.

\section{NMR studies}

Examination of the NMR spectra of the two octaneopentoxyphthalocyanines $\mathbf{3}$ and $\mathbf{8}$ at room temperature in benzene- $d_{6}$ exhibited the expected three singlets for each compound: $7.40,4.39$, and 1.17 ppm for 3 representing the aromatic, alkoxy, and tert-butyl protons, and similarly, absorptions at $8.93,3.88$, and 1.26 ppm for 8 . In the NMR spectrum at room temperature $(293 \mathrm{~K})$ of the hexadecaneopentoxyphthalocyanine 7 , however, no aromatic protons were present and one would expect two different alkoxy and 
tert-butyl absorptions representing the two different positions of the neopentoxy groups. In fact, two different peaks at $1.39(9 \mathrm{H})$ and $1.22 \mathrm{ppm}(9 \mathrm{H})$ for the two kinds of methyl signals were apparent but only a single peak at $4.55 \mathrm{ppm}(2 \mathrm{H})$ corresponding to one kind of $\mathrm{OCH}_{2}$ group could be accounted for. Though one alkoxy group was missing, a faint bulge in the baseline at $\sim 4$ to 5 ppm suggested that restricted rotation of the neopentoxy groups was the likely reason for its absence. Thus, 3,7 , and 8 were all subjected to temperature-dependent NMR studies to examine this phenomenon, well-known in other related systems including porphyrins (19), neopentylbenzenes (20-22), neopentylnaphthalenes (23), but to the best of our knowledge not phthalocyanines. Table 1 summarizes the relevant thermokinetic parameters obtained from standard lineshape analyses (24-26) for the three phthalocyanines reported in this work.

\section{Pc7}

Figure 1 shows the spectral changes observed in the $\mathrm{OCH}_{2}$ region from 235 to $355 \mathrm{~K}$ in toluene- $d_{8}$ solvent (27). The spectrum of 7 at room temperature $(293 \mathrm{~K})$ exhibited two different tert-butyl signals at 1.37 and $1.22 \mathrm{ppm}$ as expected, but only a single $\mathrm{OCH}_{2}$ peak at $4.57 \mathrm{ppm}$. Increasing the temperature of the sample during the NMR experiment resulted in the appearance of a new singlet at $4.82 \mathrm{ppm}$ which was still not as sharp as the other $\mathrm{OCH}_{2}$ peak, now at $4.49 \mathrm{ppm}$, even at $355 \mathrm{~K}$. In attempts to freeze out rotations of 7, NMR spectra were recorded at lower temperatures. At $235 \mathrm{~K}$, one $\mathrm{OCH}_{2}$ signal showed a typical $\mathrm{AB}$ splitting pattern giving a unique chemical shift centered at $4.61 \mathrm{ppm}$, presumably for the $2,3,9,10,16,17,23,24$-neopentoxy-OCH group of 7 . The $1,4,8,11,15,18,22,25$-neopentoxy-OCH groups showed what at first may be regarded as two widely separated doublets at 6.05 and $3.88 \mathrm{ppm}$, respectively. Actually, this is a second $\mathrm{AB}$ quartet centered at $5.03 \mathrm{ppm}$. Lineshape analyses of both $\mathrm{OCH}_{2}$ signals according to a two-site equal population coupled exchange model (24-26) corresponding to two pairs of diastereotopic protons confirms the steric demands imposed by the neopentoxy groups. Nearly identical results were obtained for each $\mathrm{OCH}_{2}$ group: an enthalpy of activation of about $10 \mathrm{kcal} \mathrm{mol}^{-1}$ and a negative valued entropy of activation of about $-10 \mathrm{cal} \mathrm{K}^{-1} \mathrm{~mol}^{-1}$ that contribute to a free energy of activation of about $13 \mathrm{kcal} \mathrm{mol}^{-1}$ at $298 \mathrm{~K}$. These findings give support for correlated motions in the neopentoxy groups and suggest that all of them are relatively fixed on the NMR time scale at $235 \mathrm{~K}$ and 7 occurs as a single atropisomer at $235 \mathrm{~K}$ probably with the 16 neopentoxy groups in an alternating configuration as shown in Fig. 2. Another hexadeca substituted Pc was shown to exhibit a non-planar saddle shape in the solid state (28).

\section{Pc3}

Figure 3 shows the spectral changes observed in the $\mathrm{OCH}_{2}$ region from 225 to $300 \mathrm{~K}$ in toluene- $d_{8}$ solvent. Superimposed on these spectral changes in this region is a curious phenomenon involving the sudden appearance of an anomalous peak at $5.77 \mathrm{ppm}$ at $265 \mathrm{~K}$ which becomes prominent at $255 \mathrm{~K}$ and disappears by $235 \mathrm{~K}$. We believe this to be water as the total integration of all water peaks remains constant and a temperature-dependent NMR study of the blank pure toluene- $d_{8}$ solvent also produced this peak over the same temperature range. A temperature-dependence study of the HOD peak in toluene- $d_{8}$ and other solvents has appeared but no mention was made of the sudden appearance of a new HOD absorption in a narrow temperature range (27). A sharp singlet for the $\mathrm{OCH}_{2}$ peak at $4.38 \mathrm{ppm}$ at a temperature of $310 \mathrm{~K}$ remained sharp until $225 \mathrm{~K}$ when significant broadening occurred. By $205 \mathrm{~K}$ the singlet split into two separate peaks, but at this temperature the two protons still did not $\cdot$ split each other as would be expected for diastereotopic protons. The series of spectra in this region were subjected to lineshape analyses according to an equal population uncoupled two-site exchange model (24-26). The resulting thermokinetic parameters were as follows: $\Delta H^{+}=$ $15.6 \pm 0.7 \mathrm{kcal} \mathrm{mol}^{-1}, \Delta S^{\dagger}=25.6 \pm 3.5 \mathrm{cal} \mathrm{K}^{-1} \mathrm{~mol}^{-1}$, and $\Delta G_{298}^{\dot{\dagger}}=8.0 \pm 0.3 \mathrm{kcal} \mathrm{mol}^{-1}$. By contrast no formal coalescence behaviour was observed in the aromatic and tert-butyl regions of the spectrum over the same temperature range. The aromatic peak shifts slightly from 7.37 to $7.17 \mathrm{ppm}$ while the tert-butyl protons shift negligibly from 1.21 to $1.23 \mathrm{ppm}$. However, concomitant with the splitting of the $\mathrm{OCH}_{2}$ signal as the temperature was lowered, line broadening was also observed in the tert-butyl signal suggesting that coalescence phenomena may be observable in this region at much lower temperatures than examined here.

Results for this phthalocyanine indicate that different molecular motions are occurring for 3 than for the sterically congested 7. The estimated free energy barrier in 3 is about 5 kcal mol-1 lower than for 7 (see Table 1). The large enthalpy of activation is offset by a large positive entropy of activation and is consistent with higher degrees of freedom for motion of the neopentoxy groups in 3 than in 7 . In 7 it is unlikely that rotation about the $\mathrm{C}(\mathrm{Ar}) \mathrm{O}$ or $\mathrm{O} \quad \mathrm{CH}_{2}$ bonds is facilitated since this will cause the tert-butyl groups to interfere with one another. It is known from previous dynamic NMR studies of neopentylaromatics that energy barriers for rotation about $\mathrm{C}(\mathrm{Ar})-\mathrm{CH}_{2}$ bonds are generally at least $5 \mathrm{kcal} \mathrm{mol}^{-1}$ higher than about $\mathrm{CH}_{2}-\mathrm{C}\left(\mathrm{CH}_{3}\right)_{3}$ bonds $(20$ 23). As noted above it is expected that the hydrogens of the $\mathrm{OCH}_{2}$ should be diastereotopic as in each of the corresponding groups in 7 . However, resolution was not possible since an estimate of $T_{2}^{-1}$ for both peaks in 3 at $225 \mathrm{~K}$ was nine times larger than the expected value of the coupling constant $(J)$ of $10 \mathrm{~Hz}$ as observed in 7 . Reevaluation of the lineshapes for the $\mathrm{OCH}_{2}$ region including a coupling constant contribution of $10 \mathrm{~Hz}$ gave identical thermokinetic parameters.

\section{Pc8}

The ${ }^{1}$ H NMR spectrum of 8 shows the most complicated pattern of the three phthalocyanines examined. Figs. $4 a-c$ show the spectral changes in the aromatic, $\mathrm{OCH}_{2}$, and tertbutyl regions from 225 to $300 \mathrm{~K}$ in toluene- $d_{8}$ solvent. At room temperature, three singlets at $8.95,3.85$, and $1.28 \mathrm{ppm}$ for the aromatic, $\mathrm{OCH}_{2}$, and tert-butyl groups, respectively, are observed. At $260 \mathrm{~K}$ significant broadening occurs in all peaks to the point where they almost disappear into the baseline. At $225 \mathrm{~K}$ two distinct aromatic peaks of unequal intensity are apparent at 9.31 and $8.62 \mathrm{ppm}$; similarly, two distinct tert-butyl peaks are observed at 1.39 and $1.25 \mathrm{ppm}$. 
Table 1. Summary of thermokinetic parameters obtained from lineshape analyses performed on various regions of ${ }^{1} \mathrm{H}$ NMR spectra for $\mathbf{3}, \mathbf{7}$, and $\mathbf{8}$.

\begin{tabular}{|c|c|c|c|c|c|}
\hline $\mathrm{Pc}$ & $\left.\Delta H^{+}(\mathrm{kcal} \mathrm{mol})^{-1}\right)$ & $\Delta S^{\ddagger}\left(\mathrm{cal} \mathrm{K}^{-1} \mathrm{~mol}^{-1}\right)$ & $\Delta G_{298}^{\ddagger}\left(\mathrm{kcal} \mathrm{mol}^{-1}\right)$ & $k_{\mathrm{c}}\left(\mathrm{S}^{-1}\right)$ & $T_{\mathrm{c}}(\mathrm{K})$ \\
\hline \multicolumn{6}{|l|}{$\mathrm{OCH}_{2}$ region } \\
\hline $\mathbf{3}^{a}$ & $15.6 \pm 0.7$ & $25.6 \pm 3.5$ & $8.0 \pm 1.3$ & 418 & 219 \\
\hline $7^{b}(5.03 \mathrm{ppm})$ & $10.1 \pm 0.4$ & $-9.5 \pm 1.5$ & $12.9 \pm 0.6$ & 1790 & 288 \\
\hline $7^{b}(4.61 \mathrm{ppm})$ & $10.0 \pm 0.4$ & $-11.1 \pm 1.4$ & $13.3 \pm 0.6$ & 146 & 263 \\
\hline \multirow[t]{2}{*}{$8^{c}$} & $13.8 \pm 0.5(\mathrm{~A})$ & $6.8 \pm 2.1(\mathrm{~A})$ & $11.8 \pm 0.5(\mathrm{~A})$ & $151(\mathrm{~A})$ & 251 \\
\hline & $13.8 \pm 0.5(\mathrm{~B})$ & $7.3 \pm 2.1(\mathrm{~B})$ & $11.6 \pm 0.5(\mathrm{~B})$ & $192(\mathrm{~B})$ & \\
\hline \multicolumn{6}{|c|}{ Aromatic region } \\
\hline \multirow[t]{2}{*}{$\mathbf{8}^{c}$} & $11.3 \pm 0.4(\mathrm{~A})$ & $-2.8 \pm 1.6(\mathrm{~A})$ & $12.1 \pm 0.4(\mathrm{~A})$ & $384(\mathrm{~A})$ & 259 \\
\hline & $11.3 \pm 0.4(\mathrm{~B})$ & $-2.3 \pm 1.6(\mathrm{~B})$ & $12.0 \pm 0.4(\mathrm{~B})$ & 489 (B) & \\
\hline \multicolumn{6}{|c|}{ tert-Butyl region } \\
\hline \multirow[t]{2}{*}{$8^{c}$} & $13.4 \pm 0.4(\mathrm{~A})$ & $6.2 \pm 1.6(\mathrm{~A})$ & $11.6 \pm 0.4(\mathrm{~A})$ & $93(\mathrm{~A})$ & 242 \\
\hline & $13.4 \pm 0.4(\mathrm{~B})$ & $5.9 \pm 1.6(\mathrm{~B})$ & $11.6 \pm 0.4(\mathrm{~B})$ & 73 (B) & \\
\hline
\end{tabular}

Fig. 1. ${ }^{1} \mathrm{H}$ NMR spectrum of 7 in toluene- $d_{8}$ showing spectral changes in the $\mathrm{OCH}_{2}$ region from 235 to $355 \mathrm{~K}$.

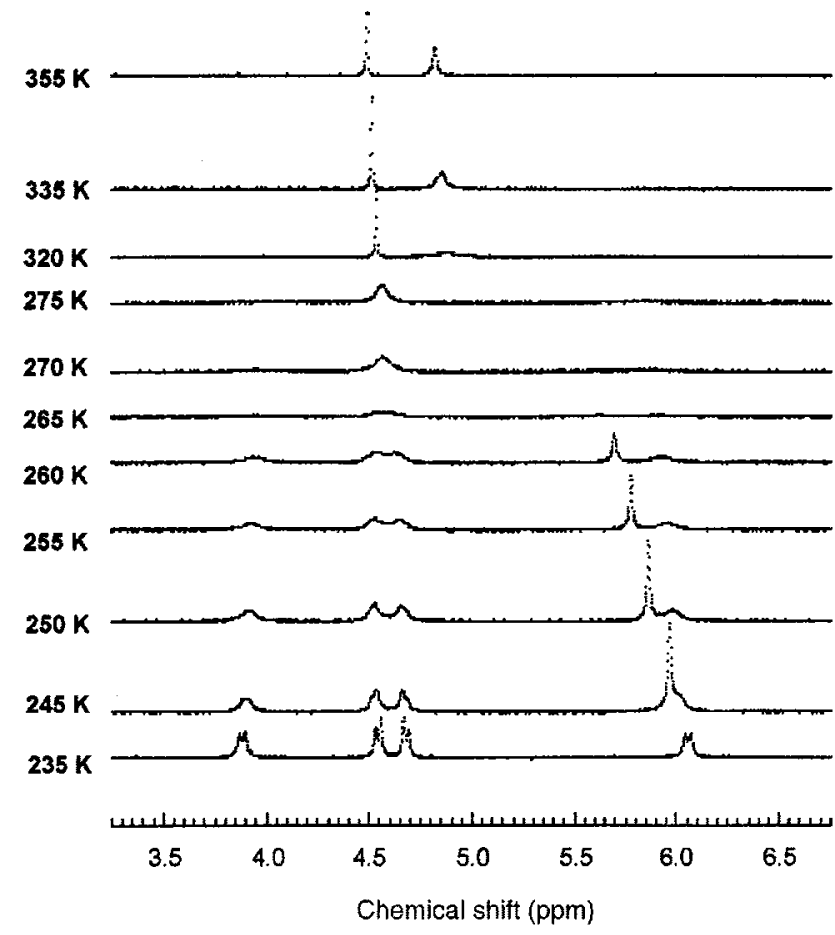

In the $\mathrm{OCH}_{2}$ region, the singlet at $3.85 \mathrm{ppm}$ becomes an asymmetric triplet as the temperature is lowered. Lineshape analyses according to an unequal population two-site exchange model (26) resulted in a population distribution of $p_{\mathrm{A}}=0.56$ and $p_{\mathrm{B}}=0.44$ and estimates of free energy barriers of about $12 \mathrm{kcal} \mathrm{mol}^{-1}$ for both aromatic and tert-butyl regions of the spectrum. These barriers are consistent with those found for 7 as would be expected for interaction between neopentoxy groups ortho to one another. Simulation of the asymmetric triplet for the $\mathrm{OCH}_{2}$ region is more complex and involves the superposition of two unequal population two-site exchange lineshapes. Again, the same population distribution was found as for the aromatic and
Fig. 2. The suggested atropisomer for 7 .

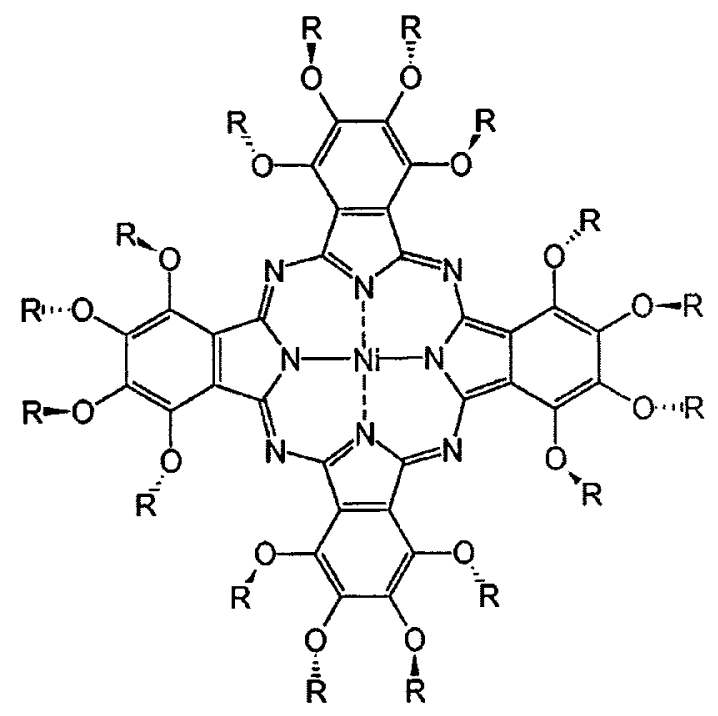

$7 \mathrm{R}=\mathrm{OCH}_{2} \mathrm{C}\left(\mathrm{CH}_{3}\right)_{3}$

tert-butyl regions with an estimated free energy barrier of about $12 \mathrm{kcal} \mathrm{mol}^{-1}$ in each case. The implication of this simulation is that each atropisomer is composed of two different $\mathrm{OCH}_{2}$ groups: at $230 \mathrm{~K}$ a minor conformer has clearly resolvable signals at 3.51 and $4.05 \mathrm{ppm}$ while a major conformer has two very closely spaced signals centered at $3.73 \mathrm{ppm}$ which are not resolvable due to pronounced line broadening. It is expected that the absence of neighbouring neopentoxy groups in the $1,4,8,11,15,18,22$, and 25 positions would make these groups more mobile and thus lead to increased broadening of all signals and particularly to complex lineshapes in the $\mathrm{OCH}_{2}$ region of the spectrum. This is clearly evident when the spectra for $\mathbf{8}$ are compared with those for 7 . Alternatively, the two distinct aromatic peaks could be due to monomer-dimer equilibria of aggregating phthalocyanines, which is more plausible for the lesshindered 8 than for 3 and 7. This hypothesis, however, was 
Fig. 3. ${ }^{1} \mathrm{H}$ NMR spectrum of 3 in toluene- $d_{8}$ showing spectral changes in the $\mathrm{OCH}_{2}$ region from 200 to $235 \mathrm{~K}$.

$235 \mathrm{~K}$

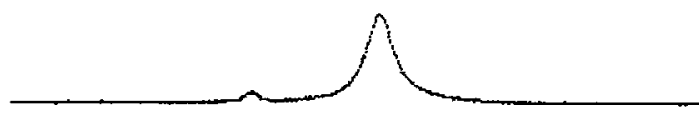

$230 \mathrm{~K}$

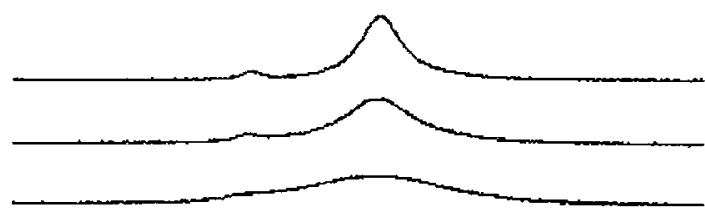

$220 K$

$215 \mathrm{~K}$

$210 K$

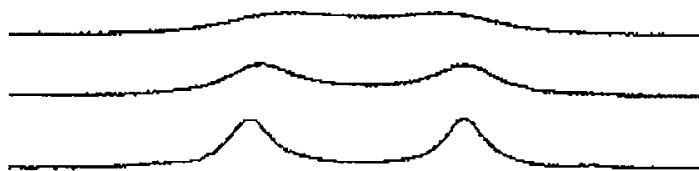

$205 K$

$200 \mathrm{~K}$
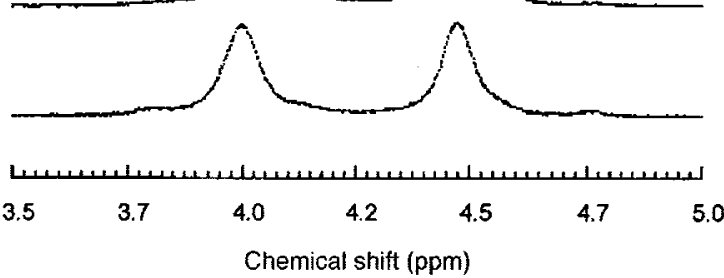

ruled out as ${ }^{1} \mathrm{H}$ NMR spectra of 8 run at $235 \mathrm{~K}$ at two different sample concentrations resulted in negligible effects on the absorption of the aromatic protons.

\section{Experimental section}

\section{General methods}

Inert atmosphere conditions were maintained using Matheson high purity argon. Magnetic stirring methods were utilized during reaction processes. Flash chromatography was performed using silica gel of particle size $40-63 \mu \mathrm{m}$. Melting points (mp) were determined using a Kofler hot stage or a Fisher Johns melting point apparatus and are uncorrected.

Nuclear magnetic resonance (NMR) spectroscopy for proton and carbon was performed using a Bruker ARX 400 high-field Fourier transform instrument at room temperature, unless noted otherwise. Chemical shifts are reported in parts per million $(\delta)$. The splitting patterns of proton resonances are described as singlets (s), doublets (d), or triplets (t). Coupling constants are reported in $\mathrm{Hz}$ for signals that are doublets. Proton-decoupled chemical shifts are reported for the ${ }^{13} \mathrm{C}$ NMR resonances.

Infrared (IR) spectra were recorded on a Unicam Matheson 3000 FT IR spectrometer using $\mathrm{KBr}$ discs for solid samples and $\mathrm{NaCl}$ discs for liquid samples. Ultraviolet-visible spectra (UV-vis) were recorded on a Hewlett-Packard HP845 IA diode array spectrophotometer. Mass spectra (MS) were recorded at $70 \mathrm{eV}$ on a Kratos Profile mass spectrometer in the EI mode for lower molecular weight molecules and in the FAB or MALDI mode for higher molecular weight molecules. Microanalyses were performed by Guelph Chemical Laboratory Ltd., Guelph, Ontario.
Fig. 4. ${ }^{1} \mathrm{H}$ NMR spectrum of 8 in toluene- $d_{8}$ showing spectral changes in $(a)$ the aromatic region; $(b)$ the $\mathrm{OCH}_{2}$ region; $(c)$ the tert-butyl region all from 225 to $300 \mathrm{~K}$.
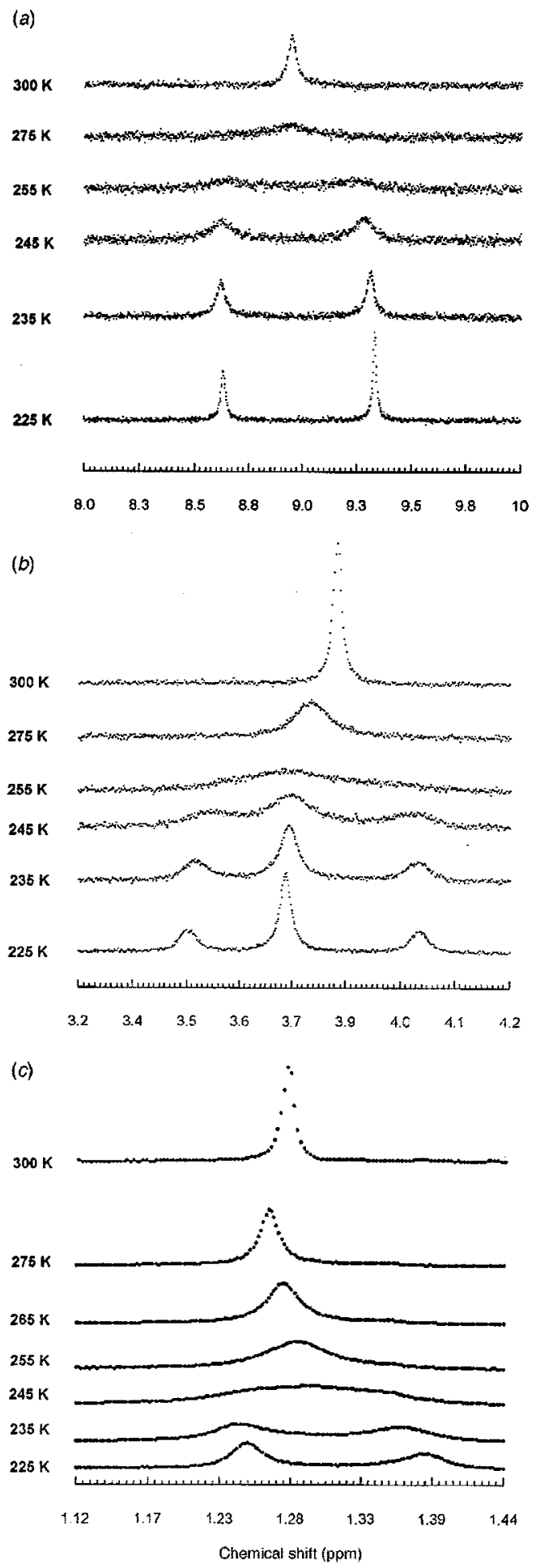

Lineshape analyses: data acquisition

All temperature studies were performed on a Bruker ARX 400 spectrometer using samples prepared in toluene- $d_{g}$ solvent. ${ }^{1} \mathrm{H}$ NMR spectra were first recorded at room tempera- 
ture and then reacquired at lower or higher temperatures in increments of $5^{\circ}$. Temperatures were read directly from a thermocouple surrounding the probe and are estimated to be within 2 to $3^{\circ}$ of the actual temperature of the samples. At each temperature the probe was allowed to equilibrate for about a minute before acquiring data. Test runs at longer equilibration periods (about $10 \mathrm{~min}$ ) gave spectra identical to those recorded at the above conditions.

\section{Lineshape analyses: data analysis}

Digitized spectra were first converted into readable format using [Spec Viewer Free Version] (Advance Chemistry Development). Relevant regions of the spectra were then subjected to lineshape analyses according to expressions given by Sandström (24), Sutherland (25), and Gutowsky and Holm (26) using KaleidaGraph 3.5 (Synergy) software. To account for spectral drift at different temperatures; spectra obtained at higher temperatures were referenced against those recorded at the lowest temperature. Simulated spectra were consistent with two-site exchange systems of either equal or unequal populations. Corresponding estimates of thermokinetic parameters and coalescence temperatures were obtained using standard Eyring expressions given previously (24-26).

\section{3,6-Dineopentoxyphthalonitrile (2)}

To $0.151 \mathrm{~g}(6.56 \mathrm{mmol})$ of sodium metal dissolved in $5 \mathrm{~mL}$ of methanol was added $500 \mathrm{mg}(3.13 \mathrm{mmol})$ of $2,3-$ dicyanohydroquinone (1). This mixture was stirred at room temperature for $2 \mathrm{~h}$. After this time, the methanol was removed under vacuum and to the resulting residue was added $10 \mathrm{~mL}$ of HMPA (caution: carcinogen) and $2.27 \mathrm{~g}$ $(9.38 \mathrm{mmol})$ of neopentyl tosylate. This mixture was stirred at $110^{\circ} \mathrm{C}$ for 4 days, cooled to room temperature, and poured into $50 \mathrm{~mL}$ of water. The product was extracted using $3 \times$ $50 \mathrm{~mL}$ of ether. The combined organic layers were washed with $100 \mathrm{~mL}$ of water, followed by $100 \mathrm{~mL}$ of brine, and then dried over $\mathrm{MgSO}_{4}$. The ether was removed under vacuum and the crude product was purified by flash silica gel column chromatography using $20 \%$ ethyl acetate and $80 \%$ hexane as the eluting solvents. The desired product was obtained as a white solid in $62 \%$ yield $(0.58 \mathrm{~g})$; mp $179-$ $181^{\circ} \mathrm{C}$. IR $(\mathrm{KBr})\left(\mathrm{cm}^{-1}\right): 2961,2229 .{ }^{1} \mathrm{H} \mathrm{NMR}\left(\mathrm{CDCl}_{3}\right) \delta$ : $7.14(\mathrm{~s}, 2 \mathrm{H}), 3.69(\mathrm{~s}, 4 \mathrm{H}), 1.10(\mathrm{~s}, 18 \mathrm{H}) .{ }^{13} \mathrm{C} \mathrm{NMR}\left(\mathrm{CDCl}_{3}\right) \delta$ : $155.6,118.7,113.0,105.1,80.0,32.2,26.4$. MS $m / z$ (rel intensity): $300\left(\mathrm{M}^{+}, 20\right), 71$ (100). Anal. calcd. for $\mathrm{C}_{18} \mathrm{H}_{24} \mathrm{~N}_{2} \mathrm{O}_{2}$ : C 71.97, $\mathrm{H}$ 8.05, N 9.33; found: C 72.00, H 8.17, N 9.36 .

\section{$1,4,8,11,15,18,22,25-O c t a n e o p e n t o x y p h t h a l o-$ cyaninato nickel (3)}

A mixture containing $0.300 \mathrm{~g}$ ( $1 \mathrm{mmol})$ of 1,4-dineopentoxyphthalonitrile (2) and $0.0912 \mathrm{~g}(0.333 \mathrm{mmol})$ of $\mathrm{NiCl}_{2}$ in $9.9 \mathrm{~mL}$ of DMAE was heated to reflux for $48 \mathrm{~h}$. After cooling at room temperature, the reaction mixture was transferred to test tubes. Precipitation of the nickel phthalocyanine was carried out by adding a $90 \%$ methanol and $10 \%$ water solution. The precipitate was collected by centrifugation and washed twice with methanol. Further pu- rification of the phthalocyanine was carried out by flash silica gel column chromatography using $50 \%$ hexane and $50 \%$ toluene as the eluting solvents. Final purification involved reprecipitation from toluene-ethanol to give the $\mathrm{NiPc}$ as a green solid in $22 \%$ yield $(69 \mathrm{mg}) ; \mathrm{mp}>300^{\circ} \mathrm{C}$. UV-vis $\lambda_{\max }$ (toluene) (log e) (nm): 748 (5.18), 674 (4.58), 444 (4.30), 330 (4.61), 308 (4.66). ${ }^{1} \mathrm{H}$ NMR (benzene- $\left.d_{6}\right)$ \&: $7.40(\mathrm{~s}$, $1 \mathrm{H}), 4.39(\mathrm{~s}, 2 \mathrm{H}), 1.17(\mathrm{~s}, 9 \mathrm{H})$. FAB-MS $m / z: 1260(\mathrm{M}+1)$. Anal. calcd. for $\mathrm{C}_{72} \mathrm{H}_{96} \mathrm{~N}_{8} \mathrm{O}_{8} \mathrm{Ni}$ : C 68.62, $\mathrm{H} 7.68, \mathrm{~N} 8.89$; found: $\mathrm{C} 68.63, \mathrm{H} 8.00, \mathrm{~N} 8.48$.

\section{3,4,5,6-Tetraneopentoxyphthalonitrile (5)}

To a stirred solution containing $0.50 \mathrm{~g}(2.5 \mathrm{mmol})$ of tetrafluorophthalonitrile (4) in $15 \mathrm{~mL}$ of DMF was added $5.5 \mathrm{~g}(62.5 \mathrm{mmol})$ of neopentyl alcohol and $8.6 \mathrm{~g}$ $(62.5 \mathrm{mmol})$ of $\mathrm{K}_{2} \mathrm{CO}_{3}$. The mixture was allowed to stir at $100^{\circ} \mathrm{C}$ under an argon atmosphere for a period of $24 \mathrm{~h}$. After cooling to room temperature, the reaction mixture was poured onto $50 \mathrm{~mL}$ of $\mathrm{H}_{2} \mathrm{O}$ and extracted using $3 \times 50 \mathrm{~mL}$ of ether. The combined organic layers were washed with $100 \mathrm{~mL}$ of $\mathrm{H}_{2} \mathrm{O}$ followed by $100 \mathrm{~mL}$ of brine and then dried over $\mathrm{MgSO}_{4}$. The solvent was removed under vacuum and the crude mixture was purified by flash silica gel column chromatography using toluene as the eluting solvent to give the product in $65 \%$ yield $(0.76 \mathrm{~g}) ; \mathrm{mp} 131-133^{\circ} \mathrm{C}$. IR $(\mathrm{KBr})$ $\left(\mathrm{cm}^{-1}\right): 2957,2232 .{ }^{1} \mathrm{H}$ NMR $\left(\mathrm{CDCl}_{3}\right) \delta: 3.81(\mathrm{~s}, 2 \mathrm{H}), 1.10$ $(\mathrm{s}, 4.5 \mathrm{H}), 1.05(\mathrm{~s}, 4.5 \mathrm{H}) .{ }^{13} \mathrm{C}$ NMR $\left(\mathrm{CDCl}_{3}\right) \delta: 153.0$, $151.9,113.3,104.4,85.6,85.2,32.8,32.6,26.7,26.6 . \mathrm{MS}$ $m / z$ (rel intensity): $472\left(\mathrm{M}^{+}, 5\right), 332$ (45), 262 (100). Anal. calcd. for $\mathrm{C}_{28} \mathrm{H}_{44} \mathrm{~N}_{2} \mathrm{O}_{4}: \mathrm{C} 71.15, \mathrm{H} \mathrm{9.38,} \mathrm{N} \mathrm{5.93;} \mathrm{found:}$ C $71.15, \mathrm{H} \mathrm{9.36,} \mathrm{N} \mathrm{6.02.}$

\section{$1,2,3,4,8,9,10,11,15,16,17,18,22,23,24,25-$ Hexadecaneopentoxyphthalocyaninato nickel (7)}

A mixture containing $0.2 \mathrm{~g}(0.42 \mathrm{mmol})$ of tetraneopentoxyphthalonitrile (5) and $33.5 \mathrm{mg}(0.14 \mathrm{mmol})$ of $\mathrm{NiCl}_{2}$ in $4.2 \mathrm{~mL}$ of DMAE was heated to reflux for $48 \mathrm{~h}$. After cooling to room temperature, the reaction mixture was transferred to test tubes. Precipitation of the nickel phthalocyanine was achieved by the addition of water. The precipitate was collected by centrifugation and washed twice with water and once with methanol. The crude phthalocyanine was further purified by flash silica gel column chromatography using $75 \%$ hexane and $25 \%$ toluene as the eluting solvents. Final purification involved reprecipitation from toluene-ethanol to give the desired $\mathrm{NiPc}$ as a green solid in $15 \%$ yield $(30 \mathrm{mg}) ; \mathrm{mp}>300^{\circ} \mathrm{C}$. UV-vis $\lambda_{\max }$ (toluene) (log e) (nm): $758(5.19), 676(4.51), 440(4.25), 386(4.44), 342$ (4.46), 314 (4.69). 'H NMR (benzene- $\left.d_{6}\right) \delta: 4.55(\mathrm{~s}, 2 \mathrm{H})$, $1.39(\mathrm{~s}, 9 \mathrm{H}), 1.22(\mathrm{~s}, 9 \mathrm{H})$. FAB-MS $m / z: 1948(\mathrm{M}+1)$. Anal. calcd. for $\mathrm{C}_{112} \mathrm{H}_{176} \mathrm{~N}_{8} \mathrm{O}_{16} \mathrm{Ni}$ : C 69.01, H 9.10, N 5.75; found: C 69.02, H 9.29, N 5.51.

\section{2,3,9,10,16,17,23,24-Octaneopentoxy- phthalocyaninato nickel (8)}

A mixture containing $0.200 \mathrm{~g}(0.667 \mathrm{mmol})$ of $1,4-$ dineopentoxyphthalonitrile and $0.053 \mathrm{~g}(0.111 \mathrm{mmol})$ of $\mathrm{NiCl}_{2}$ in 
$6.6 \mathrm{~mL}$ of DMAE was heated to reflux for $48 \mathrm{~h}$. After cooling to room temperature, the reaction mixture was transferred to test tubes. Precipitation of the nickel phthalocyanine was carried out by adding a $90 \%$ methanol and $10 \%$ water solution. The precipitate was collected by centrifugation and washed twice with methanol. Further purification of the phthalocyanine was carried out by flash silica gel column chromatography using $20 \%$ hexane and $80 \%$ toluene as the eluting solvents. Final purification of the NiPc involved precipitation using toluene-hexane. The desired NiPc was obtained as a green solid in $28 \%$ yield $(59 \mathrm{mg}): \mathrm{mp}>300^{\circ} \mathrm{C}$. UV-vis $\lambda_{\max }$ (toluene) (log e) (nm): 672 (5.17), 640 (4.52), 604 (4.46), 416 (4.37), 336 (4.59), 314 (4.73), 288 (4.78). ${ }^{1} \mathrm{H}$ NMR (benzene- $\left.d_{6}\right) \delta: 8.93(\mathrm{~s}, 1 \mathrm{H}), 3.88(\mathrm{~s}, 2 \mathrm{H}), 1.26(\mathrm{~s}$, 9H). FAB-MS $m / z: 1260(\mathrm{M}+1)$. Anal. calcd. for $\mathrm{C}_{72} \mathrm{H}_{96} \mathrm{~N}_{8} \mathrm{O}_{8} \mathrm{Ni}$ : C 68.62, H 7.68, N 8.89; found: $\mathrm{C} 69.09$, H 8.08, N 8.56.

\section{Conclusion}

Two different symmetrical octaneopentoxyphthalocyanines and a hexadecaneopentyoxyphthalocyanine were synthesized by three different routes. All of these neopentoxysubstituted phthalocyanines were highly soluble in organic solvents. The highly hindered hexadecaneopentoxyphthalocyanine (7) exhibited a highly red-shifted Q-band at $758 \mathrm{~nm}$. Variable-temperature NMR spectroscopy on an octaneopentoxyphthalocyanine (3) and particularly, the hexadecanopentoxyphthalocyanine, demonstrated restricted motion of the neopentoxy groups.

\section{Acknowledgement}

We thank the Natural Sciences and Engineering Research Council of Canada (NSERC) for grants in support of this research.

\section{References}

1. B.D. Berezin. In Coordination compounds of porphyrins and phthalocyanines. John Wiley and Sons, New York. 1981.

2. F.H. Moser and A.L. Thomas. In The phthalocyanines. Vols. 1 and 2. CRC, Boca Raton, Florida. 1983.

3. Phthalocyanines: Properties and applications. Vols. 1-4. Edited by C.C. Leznoff and A.B.P. Lever. VCH, New York. 1989 , 1992, 1993, 1996.
4. C. Piechocki, J. Simon, A. Skoulious, D. Guillon, and P. Weber. J. Am. Chem. Soc. 104, 5254 (1982).

5. C. Piechocki and J. Simon. Nouv. J. Chim. 9, 159 (1985).

6. A.W. Snow, W.R. Barger, M. Klusty, H. Wohltjen, and N.L. Jarvis. Langmuir, 2, 513 (1986).

7. D. Wohrle and M. Kaneko. Yuki Gosei Kagaku Kyokaishi, 45, 837 (1987).

8. B. Paquette and J.E. van Lier. In Photodynamic therapy: Basic principles and clinical aspects. Edited by B.W. Henderson and T.J. Dougherty. Marcel Dekker, New York. 1992. p. 145.

9. J.S. Shirk, R.G.S. Pong, S.R. Flom, H. Heckmann, and M. Hanack. J. Phys. Chem. A, 104, 1438 (2000).

10. M. Hanack and M. Lang. Adv. Mater. (Weinheim, Ger.), 6, 819 (1994).

11. W. Eberhardt and M. Hanack. Synthesis, 95 (1997).

12. M. Hanack and P. Haisch. Synthesis, 1251 (1995).

13. C.C. Leznoff, S.M. Marcuccio, S. Greenberg, A.B.P. Lever, and K.B. Tomer. Can. J. Chem. 63, 623 (1985).

14. C.C. Leznoff, P.I. Svirskaya, B. Khouw, R.L. Cerny, P. Seymour, and A.B.P. Lever. J. Org. Chem. 56, 82 (1991).

15. M. Hu, N. Brasseur, S.Z. Yildiz, J.E. Van Lier, and C.C. Leznoff. J. Med. Chem. 41, I 789 (1998).

16. C.C. Leznoff and D.M. Drew. Can. J. Chem. 74, 307 (1996).

17. G. Winter, H. Heckmann, P. Haisch, W. Eberhardt, M Hanack, L. Luer, H.-J. Egelhaaf, and D. Oelkrug. J. Am. Chem. Soc. 120, 11663 (1998).

18. A.Kh. Khanamiryan, N. Bhardwaj, and C.C. Leznoff. J. Porphyr. Phthalocy. 4, 484 (2000).

19. M. Cornia, C. Valenti, S. Cappacchi, and P. Cozzini. Tetrahedron, 54, 8091 (1998).

20. J.E. Anderson, H. Pearson, and D.I. Rawson. J. Chem. Soc. Chem. Commun. 95 (1973).

21. B. Nilsson, P. Martinson, K. Olsson, and R.E. Carter. J. Am. Chem. Soc. 96, 3190 (1974).

22. J.E. Anderson, D.J.D. Barkel, and F.S. Jorgensen. J. Chem. Soc. Perkin. Trans. 2, 199 (1988).

23. J.E. Anderson and D.J.D. Barkel. J. Chem. Soc. Perkin. Trans. 2, 1053 (1984).

24. J. Sandström. Dynamic NMR spectroscopy. Academic Press. London. 1982.

25. I.O. Sutherland. Annu. Rep. NMR Spectrosc. 4, 71 (197I).

26. H.S. Gutowsky and C.H. Holm. J. Chem. Phys. 25, 1228 (1956).

27. H.E. Gottlieb, V. Kotlyar, and A. Nudelman. J. Org. Chem. 62 , 7512 (1997).

28. I. Chambrier, M.J. Cook, and P.T. Wood. Chem. Commun. $2133(2000)$. 